\title{
Accumbens shell AMPA receptors mediate expression of extinguished reward seeking through interactions with basolateral amygdala
}

\author{
E. Zayra Millan and Gavan P. McNally ${ }^{1}$ \\ University of New South Wales, Sydney, NSW, 2052, Australia
}

\begin{abstract}
Extinction is the reduction in drug seeking when the contingency between drug seeking behavior and the delivery of drug reward is broken. Here, we investigated a role for the nucleus accumbens shell (AcbSh). Rats were trained to respond for $4 \%(v / v)$ alcoholic beer in one context (Context $A$ ) followed by extinction in a second context (Context B). Rats were subsequently tested in the training context, $A(A B A)$, or the extinction context, $B(A B B)$. Pre-test injections of the glutamate AMPA receptor antagonist, NBQX $(1 \mu \mathrm{g})$ into $A c b S h$ had no effect on renewal of alcoholic beer seeking when rats were returned to the training context (ABA). However, NBQX increased responding when rats were tested in the extinction context (ABB). In a second experiment, rats received training, extinction, and test in the same context. Pre-test injections of NBQX $(0,0.3$, and $1 \mu \mathrm{g})$ into the AcbSh dose-dependently attenuated expression of extinction. We also found that NBQX in the AcbSh had no effect on initial acquisition of extinction or the motivation to respond for reward as measured by break point on a progressive ratio schedule. Finally, we show that pharmacological disconnection of a basolateral amygdala (BLA) $\rightarrow$ AcbSh pathway via NBQX in AcbSh combined with reversible inactivation of the contralateral BLA attenuates expression of extinction. Together, these results suggest that AcbSh AMPA receptors mediate expression of extinguished reward seeking through glutamatergic inputs from the BLA.
\end{abstract}

Animals readily learn to self-administer drugs of abuse. In turn, self-administration can be reduced when the drug seeking behavior no longer yields a drug reward. This decline in drug seeking is described as extinction. Extinction does not erase the original learning that mediated previous drug seeking. Rather, it actively inhibits expression of drug seeking. There are several ways that this inhibition can be removed to reveal the original drug seeking behavior, including via re-presentations of the reinforcer (reinstatement) (de Wit and Stewart 1981), presentations of a drugassociated stimulus (cue-induced reinstatement) (de Wit and Stewart 1981), or context change between extinction and test (renewal or context-induced reinstatement) (Crombag and Shaham 2002). Despite increasing knowledge regarding neural mechanisms that reveal or reinstate drug seeking following extinction (Kalivas and Volkow 2005; Crombag et al. 2008), much less is known about the mechanisms of extinction itself. Yet, extinction causes a reduction in drug seeking behavior, and understanding its mechanisms may contribute to promoting long term abstinence from drug seeking.

Studies based on reversible inactivation manipulations point to a functional role for the nucleus accumbens shell (AcbSh) in mediating expression of extinction in drug seeking animals. In these studies, responding for a reward such as intravenous cocaine (Peters et al. 2008) or alcoholic beer (Millan et al. 2010) is trained, extinguished, and then tested under extinction conditions. Reversible inactivation of AcbSh attenuates expression of extinction when injections are made prior to test, whereas similar inactivation prior to initial extinction learning has no impact on extinction learning. These findings suggest that AcbSh is recruited specifically to enable inhibition of reward seeking during expression of extinction. The recruitment of the AcbSh during

'Corresponding author.

E-mail g.mcnally@unsw.edu.au; fax 61-2-93853641.

Article is online at http://www.learnmem.org/cgi/doi/10.1101/lm.2144411. extinction is also supported by studies showing extinctiondependent changes in glutamate receptor expression within the AcbSh of cocaine-seeking rats (Sutton et al. 2003; Self et al. 2004; Ghasemzadeh et al. 2009). For example, extinction of cocaine seeking significantly increases the expression of AMPA receptor subunits (GluR1 and GluR2/3) in AcbSh, and this expression is positively correlated with the magnitude of behavioral extinction expressed (Sutton et al. 2003). Moreover, viralmediated overexpression of GluR1 subunits in AcbSh inhibits cocaine seeking (Sutton et al. 2003). Although these findings suggest that AMPA-type glutamate receptors in AcbSh may be necessary for expression of extinction, the extinction-dependent up-regulation of AMPA receptors occurred only in cocaine- but not sucrose-trained rats. Therefore, the involvement of AMPA receptors in the extinction of responding for reinforcers other than cocaine is unknown. In addition, the effects of pharmacological AMPA receptor antagonism on expression of extinction of drug seeking are unknown.

A role for AcbSh glutamate receptors in extinction of reward seeking is of interest given that the AcbSh receives glutamatergic inputs from several cortical, thalamic, and limbic sites involved in reward-related behavior, including infralimbic prefrontal cortex (ilPFC), basolateral amygdala (BLA), and ventral hippocampus (Robinson and Beart 1988; Kita and Kitai 1990; Wright et al. 1996; Groenewegen et al. 1999). Previous findings based on functional disconnection procedures suggest that AcbSh interacts with ilPFC to enable expression of extinguished cocaine seeking (Peters et al. 2008). However, the BLA—primarily its caudal subregion-is another glutamatergic input to the AcbSh that might be recruited during extinction. Consistent with this possibility, bupivacaine-induced inactivation of the caudal BLA prior to initial acquisition of extinction training retarded extinction learning as expressed on a subsequent day of extinction (McLaughlin and Floresco 2007). Single unit recordings show that a subpopulation of neurons primarily within the caudal BLA is recruited during 
extinction of sucrose seeking and related to behavioral responding during extinction (Tye et al. 2010). Moreover, AcbSh-targeted projections from BLA show increased neuronal activation when rats are returned to an extinction-associated context (Hamlin et al. 2009). Therefore, AcbSh AMPA receptor contributions to extinction of reward seeking may be dependent on glutamatergic projections from BLA. However, the functional involvement of a $\mathrm{BLA} \rightarrow$ AcbSh pathway in extinction remains unknown.

The present experiments investigated a functional role for AcbSh AMPA-type receptors and their serial interactions with the BLA in extinction of alcoholic beer seeking. First, we used a context-induced reinstatement (renewal) paradigm to assess the behavioral specificity of AcbSh AMPA receptor involvement in both reinstatement and extinction expression. Rats underwent alcoholic beer self-administration in one context (Context A) before extinction training in a second context (Context B). Rats subsequently received microinjections of the AMPA receptor antagonist NBQX and were tested in both the training context, $\mathrm{A}(\mathrm{ABA})$, and the extinction context, $\mathrm{B}(\mathrm{ABB})$. We next examined the dose-dependent effects of NBQX on extinguished responding and the behavioral impact of NBQX on other measures of reward seeking and motivation, via studying initial extinction learning and performance on a progressive ratio schedule of reinforcement. Finally, using a contralateral disconnection procedure, we examined whether BLA projections interact with AcbSh AMPA receptors to enable the behavioral expression of extinction of alcoholic beer seeking.

\section{Results}

\section{Experiment 1: Effects of NBQX on expression of extinction and renewal of reward seeking}

To examine whether AMPA receptors in AcbSh are necessary for expression of extinction and renewal of alcoholic beer seeking, an ABA renewal paradigm was used. Rats underwent self-administration and extinction training in Contexts $\mathrm{A}$ and $\mathrm{B}$, respectively. They were subsequently allocated into two groups, saline or NBQX $(1.0 \mu \mathrm{g})$, and tested in both Contexts A (the training context) and $B$ (the extinction context) over two consecutive days, counterbalanced in order. There was no beer present on test. Rats received microinjections immediately prior to each test, and treatment groups were maintained across test contexts. The question of interest was whether AcbSh infusions of the AMPA antagonist, NBQX, would prevent the expression of extinction.

\section{Histology}

Bilateral placement of injection tips is shown in Figure 1A. Three rats were excluded from analyses due to misplaced cannulae. Final group sizes were: saline $(n=8)$ and NBQX $(n=10)$.

\section{Behavior}

All rats acquired high levels of responding during training. On the last day of training, the mean \pm SEM numbers of active and inactive nosepokes were $82.78 \pm 10.11$ and $3.22 \pm 0.65$, respectively. There were no significant differences between groups $\left(F_{(1,16)}\right.$ values $<1, P$ values $>0.05$ ); all rats made significantly more active than inactive nosepokes $\left(F_{(1,16)}=143.64, P<0.001\right)$.

Mean \pm SEM responses during extinction are shown in Figure 1B. During extinction, there were no differences between groups $\left(F_{(1,16)}\right.$ values $<1.66, P$ values $\left.>0.05\right)$; all rats made significantly more active than inactive nosepokes $\left(F_{(1,16)}=166.79, P<\right.$ 0.001), and responding significantly decreased across days of extinction $\left(F_{(1,16)}=90.30, P<0.001\right)$. This decrease was greater on the active than inactive nosepoke $\left(F_{(1,16)}=50.81, P<0.001\right)$.
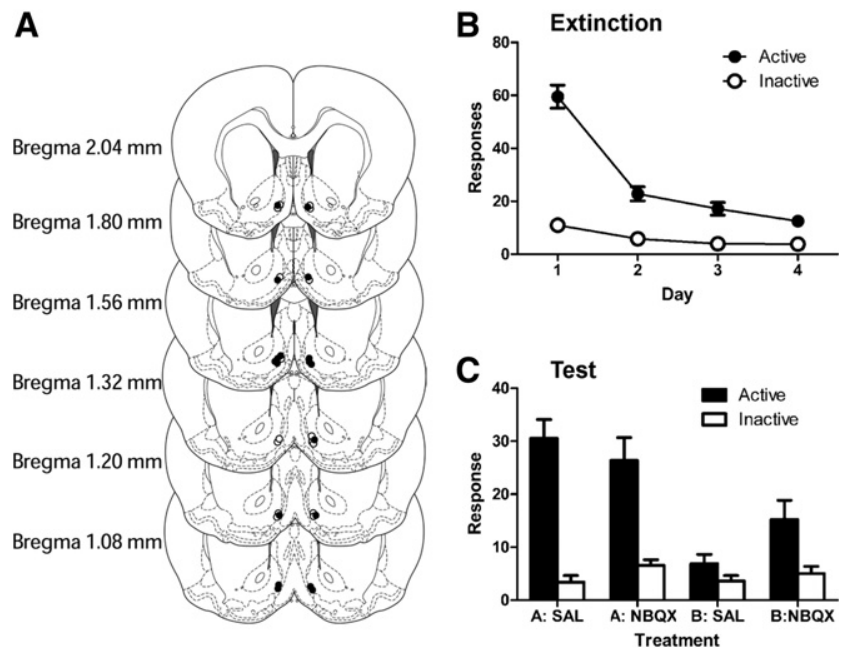

Figure 1. (A) Microinfusion cannula placements for Experiment 1 as verified on Nissl-stained sections: saline (SAL, empty circles) and $1.0 \mu \mathrm{g}$ NBQX (black-filled circles). In all figures, symbols represent the most ventral point of the cannula track, indicated on coronal sections adapted from Paxinos and Watson (2007) (with permission from Elsevier (C) 2007). (B) Experiment 1: mean \pm SEM numbers of active and inactive responses during extinction. (C) Experiment 1: mean $\pm S E M$ numbers of active and inactive responses during test in Context $A$ and Context B. Rats were tested in both contexts in counterbalanced order. Saline or NBQX $(1.0 \mu \mathrm{g})$ was administered immediately prior to test.

Figure $1 \mathrm{C}$ shows the mean \pm SEM number of responses on test. Rats were tested in both Contexts A and B under extinction conditions. There was no overall difference between infusion groups, averaged across context and manipulanda (active and inactive nosepokes) $\left(F_{(1,16)}=2.14, P>0.05\right)$. There was overall greater responding in the training context $(\mathrm{ABA})$ than the extinction context $(\mathrm{ABB})\left(F_{(1,16)}=20.32, P<0.05\right)$. There was overall more responding on the active than inactive nosepoke $\left(F_{(1,16)}=\right.$ $74.04, P<0.05)$. There was also a context $\times$ manipulanda interaction $\left(F_{(1,16)}=30.65, P<0.05\right)$, confirming that context-induced reinstatement $(\mathrm{ABA})$ was greater for the active than inactive nosepokes. Importantly, analyses of group differences showed no difference between NBQX and saline infusions on active $\left(F_{(1,16)}<\right.$ $1, P>0.05)$ or inactive $\left(F_{(1,16)}=4.27, P>0.05\right)$ nosepokes when rats were tested in the training context $A$. There was also no difference between NBQX and saline infusions on inactive nosepokes in Context $\mathrm{B}\left(F_{(1,16)}<1, P>0.05\right)$. However, NBQX infusions significantly increased active nosepokes in Context $\mathrm{B}\left(F_{(1,16)}=5.29\right.$, $P<0.05)$. These results show that AcbSh AMPA receptor antagonism attenuates the expression of extinction of alcoholic beer seeking and that these same infusions do not affect contextinduced reinstatement.

\section{Experiment 2: Dose response effects of NBQX on expression of extinction}

To further investigate the role of AcbSh AMPA receptors in expression of extinction, we characterized the dose response properties of NBQX infusions into AcbSh on expression of extinction, where training and extinction occurred in the same context. Rats were trained to respond for alcoholic beer followed by extinction training. They were subsequently tested in a repeated-measures design for expression of extinction under three treatment conditions$0 \mu \mathrm{g}$ (saline), $0.3 \mu \mathrm{g}$, and $1.0 \mu \mathrm{g}$ NBQX-counterbalanced in order. The highest dose was selected based on previous studies 
of NBQX on appetitive motivation (Maldonado-Irizarry et al. 1995). Test conditions were identical to extinction, with one infusion-free extinction session between each test. Microinjections were made into the AcbSh immediately prior to each test.

\section{Histology}

Bilateral placement of injection tips is shown in Figure 2A. Four rats were excluded due to misplaced or blocked cannulae. Eight rats were included in the final analyses.

\section{Behavior}

All rats acquired high levels of responding during training. On the last day of training, the mean \pm SEM numbers of active and inactive nosepokes were $82.13 \pm 15.11$ and $3 \pm 0.76$, respectively. During training, all rats made significantly more responses on the active than inactive nosepoke $\left(F_{(1,7)}=64.23, P<0.001\right.$, MSE $=3089.18$.

Mean \pm SEM responses during extinction training are shown in Figure 2B. During extinction training, rats made significantly more active than inactive nosepokes $\left(F_{(1,7)}=85.00, P<0.001\right.$, MSE $=116.57)$. Overall responding significantly decreased across days of extinction $\left(F_{(1,7)}=84.97, P<0.001\right.$, MSE $\left.=201.52\right)$, and this decrease was greater on the active than inactive nosepoke $\left(F_{(1,7)}=103.42, P<0.001, \mathrm{MSE}=88.63\right)$.

Figure $2 \mathrm{C}$ shows the mean \pm SEM number of responses on test. Testing conditions were identical to extinction training. Overall, $1.0 \mu \mathrm{g}$ NBQX significantly increased responding relative to saline treatment $\left(F_{(1,7)}=12.07, P<0.01\right.$, MSE $\left.=36.05\right)$, and this increase was greater on the active than inactive nosepoke $\left(F_{(1,7)}=8.05, P<0.05, \mathrm{MSE}=13.05\right)$. Averaged across treatment conditions, the number of active nosepokes was significantly greater than inactive nosepokes $\left(F_{(1,7)}=13.52, P<0.05\right.$, MSE $=$ 22.19). NBQX treatment had no effect on performance during the subsequent infusion-free day of extinction.

A
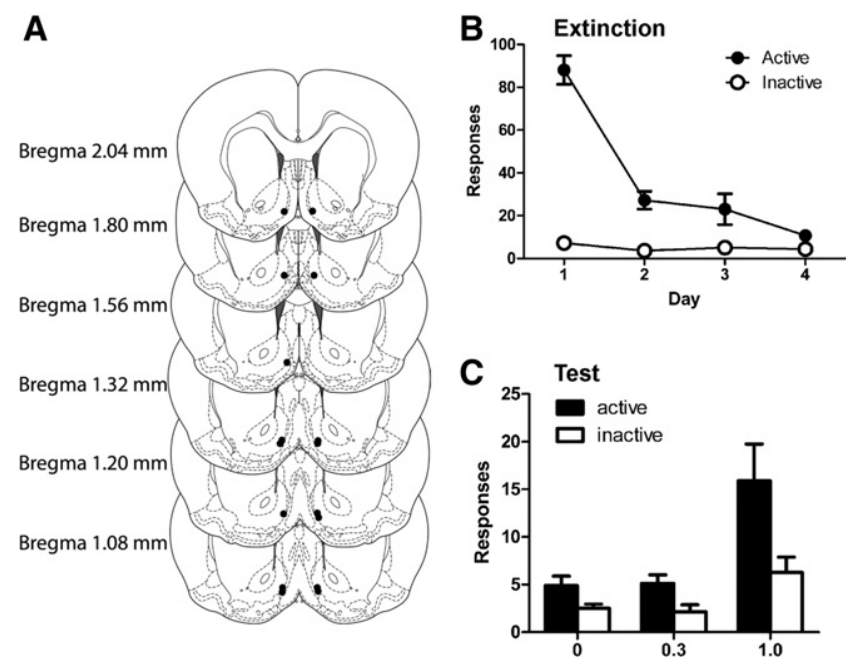

Figure 2. (A) Microinfusion cannula placements for Experiment 2 as verified on Nissl-stained sections: saline (SAL, empty circles) and NBQX (black-filled circles). ( $B, C)$ Experiment 2: mean \pm SEM numbers of active and inactive responses during extinction and subsequent test, respectively. Rats were tested under all NBQX treatment conditions $(0 \mu \mathrm{g}$, $0.3 \mu \mathrm{g}$, and $1.0 \mu \mathrm{g}$ ) in a within-subjects design, counterbalanced for test order. Rats received saline infusions when allocated to the $0 \mu \mathrm{g}$ treatment condition.

\section{Experiment 3: Effects of NBQX on extinction acquisition and progressive ratio}

We next assessed the effects of NBQX on two measures of nonextinguished reward seeking: initial extinction learning and responding on a progressive ratio schedule of reinforcement. The former was selected to determine whether NBQX impaired extinction learning. The progressive ratio test was selected to determine whether the effects of NBQX on expression of extinction in Experiments 1 and 2 might be due to a general effect of NBQX increasing the motivation to respond for a reward. All sessions took place in the same context. Rats received selfadministration training, followed by two consecutive days of extinction test. There were two groups, saline and NBQX $(1.0 \mu \mathrm{g})$, matched on the average number of active nosepokes made over the last day of self-administration. Immediately prior to test (i.e., first extinction session) rats received microinfusion into AcbSh as per treatment group. Rats were retested the following day under infusion-free extinction conditions. We reasoned that if NBQX interfered with extinction learning on the first day of extinction, then group NBQX should respond more than saline-treated rats on the second day of extinction. Subsequent to extinction tests, rats received three consecutive days of alcoholic beer self-administration (FR-1) to re-establish responding. They were then tested on the following day on a progressive ratio schedule. Immediately prior to the progressive ratio test, rats received microinfusion of either saline or $1.0 \mu \mathrm{g}$ NBQX. Therefore, rats were tested twice using a crossover design for drug infusion-those receiving saline treatment during the extinction learning test subsequently received NBQX treatment in the progressive ratio test, and vice versa.

\section{Histology}

Bilateral placement of injection tips are shown in Figure 3A. Two rats were excluded due to misplaced cannulae. Twelve rats were included in the final analysis. Final group sizes: $n=5$ and $n=7$.

\section{Behavior}

All rats acquired high levels of responding during training. On the last day of acquisition training, the mean \pm SEM numbers of active and inactive nosepokes were $60.42 \pm 11.84$ and $2.08 \pm$ 0.51 , respectively. During training, there were no differences between groups $\left(F_{(1,10)}\right.$ values $<1, P$ values $\left.>0.05\right)$; all rats made significantly more active than inactive nosepokes $\left(F_{(1,10)}=\right.$ 141.70, $P<0.001)$.

Mean \pm SEM responses on the two days of extinction test are shown in Figure 3B. Across groups, rats made significantly more active than inactive nosepokes $\left(F_{(1,10)}=55.46, P<0.001\right)$, and responding significantly decreased from day 1 to day 2 of extinction $\left(F_{(1,10)}=11.99, P<0.01\right)$, confirming the acquisition of extinction. This decrease was greater on the active than inactive nosepoke $\left(F_{(1,10)}=12.60, P<0.01\right)$.

There was no main effect of group $\left(F_{(1,10)}<1, P>0.05\right)$ nor an effect of NBQX on the decrease in responding from day 1 to day 2 of extinction (group $\times$ day interaction, $F_{(1,10)}\langle 1, P\rangle$ 0.05). In addition, there was no effect of AcbSh infusions of NBQX on either day 1 (the day of infusion) or day 2 (the infusionfree test) of extinction $\left(F\right.$ values $_{(1,10)}<1, P$ values $\left.>0.05\right)$. These results show that, in contrast to their effects on expression of extinction, AcbSh infusions of NBQX have no significant effect on the acquisition of extinction learning. That is, AcbSh infusions of NBQX did not prevent the decrement in responding observed between day 1 and day 2 of extinction training.

Mean \pm SEM responses and break point during the progressive ratio test are shown in Figure 3C (left and right panels, 
A
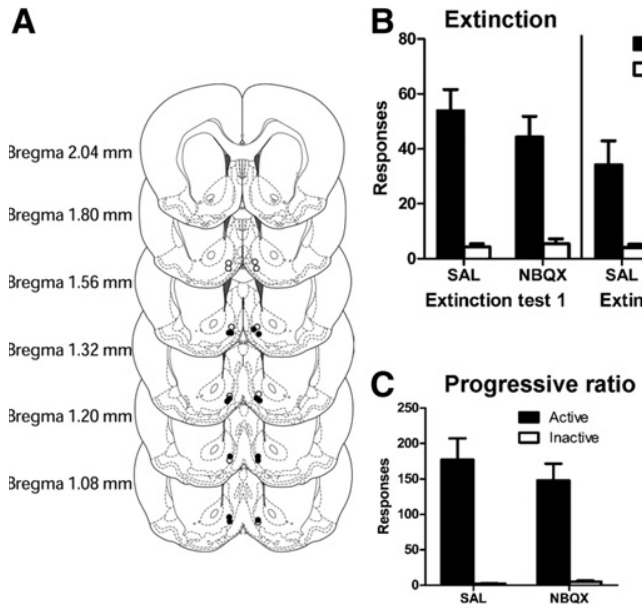

Active Inactive (1)

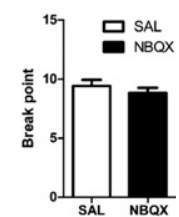

Figure 3. (A) Microinfusion cannula placements for Experiment 3 were verified on Nissl-stained sections. In the extinction learning experiment, groups were: saline (SAL, empty circles) and $1.0 \mu \mathrm{g} \mathrm{NBQX}$ (black-filled circles). Groups were reversed for the progressive ratio study. (B) Experiment 3-NBQX $(1.0 \mu \mathrm{g})$ effects on extinction learning: mean \pm SEM numbers of active and inactive responses during test (extinction days 1 and 2). Rats received infusions of saline or NBQX into AcbSh immediately before test (extinction day 1 ) and not on extinction day 2. (C) Experiment 3-NBQX $(1.0 \mu \mathrm{g})$ effects on progressive ratio test: mean \pm SEM numbers of total active and inactive responses during test (left panel) and total number of infusions received (i.e., break point) on test (right panel).

respectively). There were no significant differences between groups on active and inactive responding $\left(F\right.$ values $_{(1,10)}<1, P$ values $>0.05)$. All rats made significantly more active than inactive responses on test $\left(F_{(1,10)}=77.96, P<0.001\right)$. There was no significant difference between groups on break point $\left(F_{(1,10)}<1, P>\right.$ $0.05)$. These results show that NBQX did not affect performance on a progressive ratio schedule. It is possible that the null results from the progressive ratio test were due to a ceiling effect. However, we consider this unlikely because NBQX had no effect on renewed responding (Experiment 1) or on the first day of extinction (Experiment 3) where overall levels of responding were lower. Moreover, a progressive ratio schedule is sensitive to measuring increases in break point (e.g., Jewett et al. 1995).

\section{Experiment 4: Effects of BLA-AcbSh disconnection on expression of extinction}

Experiments 1 and 2 demonstrate that AcbSh AMPA receptors are necessary for the expression of extinction. The AcbSh receives glutamatergic inputs from the BLA, a structure shown to be recruited during expression of extinction of reward seeking (McLaughlin and Floresco 2007; Hamlin et al. 2009; Tye et al. 2010). To assess the possibility that glutamatergic BLA inputs into AcbSh may be required for the expression of extinction, we functionally disconnected the BLA $\rightarrow$ AcbSh pathway. This involved a unilateral injection of NBQX $(1.0 \mu \mathrm{g})$ into the AcbSh in combination with unilateral reversible inactivation of the BLA using $G_{A B A}$ and $\mathrm{GABA}_{\mathrm{A}}$ agonists, baclofen $(1.0 \mathrm{mM})$ and muscimol hydrobromide $(0.1 \mathrm{mM})(\mathrm{B} / \mathrm{M})$, in the contralateral hemisphere. A unilateral infusion of NBQX ensures that glutamatergic afferents to the AcbSh (including those from BLA) are disrupted, and, in the contralateral hemisphere, reversible inactivation of the BLA prevents transmission from the BLA (but not from other AcbSh afferents). Therefore, on the basis that projections from the BLA to AcbSh are both unidirectional and ipsilateral, the contralateral disconnection

procedure used here disrupts AMPA-dependent communication between the BLA and AcbSh. Rats were trained to respond for alcoholic beer reward followed by extinction and test, as in Experiment 2. All sessions were conducted in the same context. Rats were tested in a repeated-measures design for expression of extinction under three treatment conditions: sham (contralateral saline in AcbSh + BLA), ipsilateral NBQX (AcbSh) + B/M (BLA), and contralateral NBQX (AcbSh) $+\mathrm{B} / \mathrm{M}$ (BLA), counterbalanced in order. As in Experiment 2, test conditions were identical to extinction, with one infusion-free extinction session between each test. Microinjections were made immediately prior to each test.

\section{Histology}

Bilateral placement of injection tips are shown in Figure 4, C and $\mathrm{D}$ for AcbSh and BLA, respectively. Seven rats were excluded due to misplaced cannulae. Fourteen rats were included in the final analysis.

\section{Behavior}

All rats acquired high levels of responding during training. On the last day of acquisition training, the mean \pm SEM numbers of active and inactive nosepokes were $64.86 \pm 14.14$ and $3.57 \pm$ 1.14 , respectively. During training, rats made significantly more responses on the active than inactive nosepoke $\left(F_{(1,13)}=131.63\right.$, $P<0.001, \mathrm{MSE}=2579.56$ ).

Mean \pm SEM responses during extinction training are shown in Figure 4A. During extinction, rats responded significantly more on the active than inactive nosepokes $\left(F_{(1,13)}=61.54, P<0.001\right.$, MSE $=383.105)$. Overall responding significantly decreased across days of extinction $\left(F_{(1,13)}=34.27, \quad P<0.001\right.$, MSE $=$ $425.20)$, and this decrease was greater on the active than inactive nosepoke $\left(F_{(1,13)}=41.86, P<0.001, \mathrm{MSE}=237.39\right)$. Figure $4 \mathrm{~B}$ shows the mean \pm SEM number of responses on test. Testing conditions were identical to extinction training. Overall, responding was greater on the active than inactive nosepoke $\left(F_{(1,13)}=65.36\right.$, $P<0.001, \mathrm{MSE}=49.44)$. There were no significant differences between sham and ipsilateral treatment groups $\left(F_{(1,13)}=2.05, P\right.$ values $>0.05$, MSEs $=12.69-45.23)$. In contrast, contralateral disconnection of BLA and AcbSh significantly increased responding relative to the sham treatment group $\left(F_{(1,13)}=9.07, P<0.01\right.$, MSE $=114.39)$, and this increase was greater on the active than the inactive nosepoke $\left(F_{(1,13)}=9.31, P<0.01, \quad \mathrm{MSE}=52.24\right)$. Treatments had no effects on performance during the subsequent infusion-free day of extinction.

\section{Discussion}

These studies show that expression of extinction of alcoholic beer seeking depends on glutamatergic activation of AcbSh AMPA receptors. AcbSh infusions of the AMPA antagonist NBQX dose-dependently disrupted expression of extinguished responding. AcbSh infusions of NBQX were ineffective on measures of nonextinguished responding, including context-induced reinstatement, initial extinction acquisition, and responding on a progressive ratio schedule. Therefore, the present results suggest a specific role for AcbSh AMPA receptors in mediating expression of extinction. They support recent findings that reversible inactivation of AcbSh via infusions of GABA agonists similarly disrupt the expression but not initial acquisition of extinction in drug seeking rats (Peters et al. 2008; Millan et al. 2010). The present findings are also consistent with a role for AMPA GluR1 receptor subunits in extinction of cocaine seeking rats (Sutton et al. 2003; Engblom et al. 2008) and suggest that AcbSh AMPA 
A

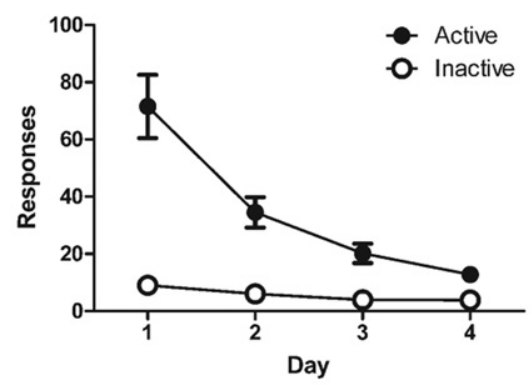

B

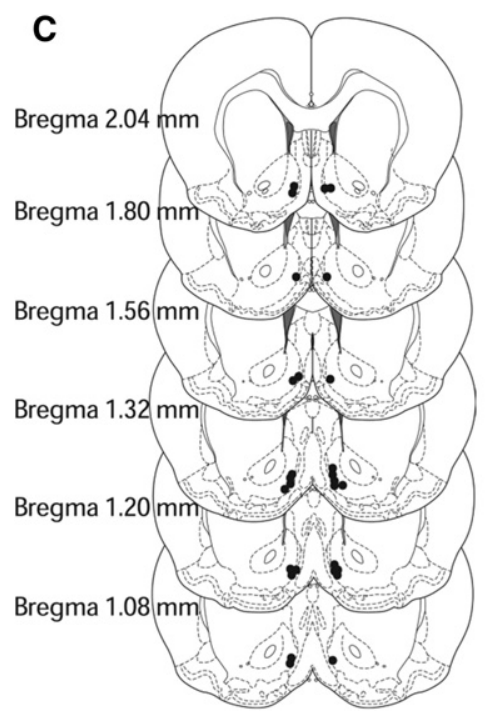

D

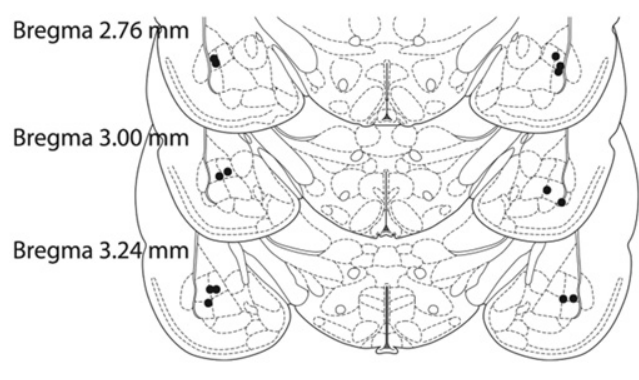

Figure 4. $(A, B)$ Experiment 4: mean \pm SEM numbers of active and inactive responses during extinction and subsequent test, respectively. Rats were tested under all treatment conditions (sham, ipsilateral, and contralateral) in a within-subjects design, counterbalanced for test order. $(C, D)$ Microinfusion cannula placements in AcbSh and BLA, respectively, for Experiment 4 as verified on Nissl-stained sections. BLA cannula placements were unilateral.

receptors may mediate the expression of extinguished reward seeking across different reinforcers. Finally, using a functional disconnection procedure, we show that a BLA $\rightarrow$ AcbSh pathway mediates expression of extinction of alcoholic beer seeking.

\section{AMPA-receptors in AcbSh mediate extinction expression}

In the present study, NBQX attenuated the expression of extinction in rats with a history of extinction training, regardless of whether extinction occurred in a context that was identical (i.e., an AAA design) or distinct (i.e., an $\mathrm{ABB}$ design) from the selfadministration context. This supports a specific role for AcbSh AMPA receptors in extinction expression. Moreover, these effects of NBQX are not likely due to nonspecific behavioral activation or a general effect on the motivation to work for a reward, since similar infusions were ineffective on measures of initial extinction learning and on responding in a progressive ratio schedule, respectively. This is consistent with previous findings that reversible inactivation of AcbSh using the $\mathrm{GABA}_{\mathrm{A}}$ agonist muscimol was similarly ineffective on break point for food reinforcement (Zhang et al. 2003). Finally, it is unlikely that NBQX impacted on the animals' level of food deprivation since both overall responding and break point on a progressive ratio schedule are increased by food deprivation (Jewett et al. 1995), and, in the present study, there was no effect of NBQX on either of these measures. Interestingly, AcbSh infusions of NBQX were ineffective on responding under context-induced reinstatement (ABA test, Experiment 1), suggesting that a history of extinction training alone is insufficient to detect an effect of NBQX on test. Rather, NBQX impacts specifically on expression of extinction.

One possibility is that the reinstatement of extinguished reward seeking following blockade of AcbSh AMPA receptors reflects a role for AcbSh in gating reward-directed responding (Taha and Fields 2005, 2006; Krause et al. 2010). Single unit recordings show that a subpopulation of accumbal neurons abruptly reduces their spike firing during reward seeking and appetitive responding, and that electrical stimulation of these cells suppresses consummatory behavior (Taha and Fields 2005, 2006; Krause et al. 2010). This suggests that a pause or reduction in AcbSh neuronal activity is required for expression of reward seeking. A similar reduction in AcbSh neuronal activity may be achieved following AcbSh injections of NBQX. Consistent with this possibility, a locally applied AMPA receptor antagonist, CNQX, blocks spontaneously active as well as glutamate-induced neuronal activity in the striatum (Sandstrom and Rebec 2003). Moreover, on the basis that accumbal neurons typically have hyperpolarized resting potentials and little spontaneous firing activity (O'Donnell and Grace 1995; Hu and White 1996), it has been suggested that pharmacological blockade of AMPA receptors potentially "turns off" accumbal neurons (Tzschentke and Schmidt 2003; Yun et al. 2004). Therefore, in the present study, a reduction in AcbSh neuronal activity following AMPA receptor blockade might account for the observed reinstatement of the previously extinguished reward seeking response.

The medium-spiny GABAergic projection neurons of the AcbSh directly target the lateral hypothalamus (LH). AcbSh neurons can, therefore, exert direct inhibitory control over the LH (Sano and Yokoi 2007). Reductions in the activity of AcbSh projection neurons to LH may disinhibit LH neurons, thereby promoting reward seeking. Conversely, increases in the activity of these AcbSh projecting neurons may reduce reward seeking. There are several findings consistent with this possibility: extinction training up-regulates AMPA receptor subunit expression in AcbSh (Sutton et al. 2003); activation of AcbSh projection neurons to $\mathrm{LH}$ is associated with the behavioral expression of extinction (Marchant et al. 2009); and the reinstatement of extinguished responding induced by general inactivation of AcbSh depends on LH neuronal activation (Millan et al. 2010). Thus, extinction may involve up-regulation of AMPA receptor signaling in AcbSh neurons projecting to LH. Infusions of NBQX into AcbSh might, in turn, reduce this signaling. thereby disinhibiting LH and reinstating reward seeking (Maldonado-Irizarry et al. 1995; Stratford and Kelley 1999; Millan et al. 2010). 


\section{BLA projections to AcbSh are necessary} for the expression of extinction

In the present study, contralateral, but not ipsilateral, disconnection of the BLA from AcbSh disrupted the expression of extinction. This finding suggests that glutamatergic transmission in a BLA $\rightarrow$ AcbSh pathway is required for the expression of extinguished reward seeking. It is also consistent with studies supporting a role for the BLA in extinction (Fuchs et al. 2002; McLaughlin and Floresco 2007) and may reflect a role for this pathway in translating the extinction memory into behavioral inhibition of reward and drug seeking. Indeed, BLA neurons projecting to AcbSh are recruited during expression of extinction (Hamlin et al. 2009).

Anatomically, glutamatergic afferents from the BLA directly and monosynaptically target accumbal medium- spiny projection neurons (Robinson and Beart 1988; Kita and Kitai 1990; Kirouac and Ganguly 1995; O’Donnell and Grace 1995). Projections to AcbSh are largely derived from caudal portions of the BLA (Heimer et al. 1997; Hamlin et al. 2009). The microinjection cannulae in Experiment 4 were targeted to the caudal BLA to increase the probability of affecting these AcbSh projection neurons. Importantly, BLA afferents terminate proximally to AcbSh cells that project to the LH, with BLA fiber terminals appearing to make contact on LH-projecting AcbSh cells (Kirouac and Ganguly 1995). Based on this pattern of connectivity, it is possible that extinction is expressed, at least in part, via an amygdalostriato-hypothalamic circuit. ilPFC interactions with AcbSh are also critical for the expression of extinction (Peters et al. 2008), although little is known of how ilPFC and amygdala interact via reciprocal projections or through their convergence on AcbSh cells to enable expression of extinction. One possibility is that during extinction expression, AcbSh integrates information from cortical (Peters et al. 2008), amygdala (present experiments), and potentially hippocampal inputs (O'Donnell and Grace 1995; O'Donnell et al. 1999) to gate the inhibition of drug and reward seeking.

However, a role for BLA in extinction of drug seeking is likely to be complex because bilateral reversible inactivation of the BLA does not reinstate cocaine seeking behavior; instead, it is ineffective on performance of an extinguished cocaine seeking response, regardless of whether extinction occurred in a context identical to or distinct from the training context (Fuchs et al. 2004; Peters et al. 2008). Moreover, bilateral reversible inactivation can enhance cue-induced reinstatement (McLaughlin and Floresco 2007) or prevent reinstatement of drug and reward seeking (e.g., McLaughlin and See 2003; Fuchs et al. 2004; Peters et al. 2008). Therefore, there may be a dual role for BLA in inhibiting and enabling reward seeking, and this may be mediated by distinct projections from BLA. The present data show a role for a BLA $\rightarrow$ AcbSh pathway in the inhibition of reward seeking during extinction expression. However, rostral BLA neurons are selectively activated, as indexed by expression of the Fos protein, during reinstatement (Hamlin et al. 2009), and these neurons project to the PFC (Hoover and Vertes 2007). Studies based on pharmacological disconnection of the rostral BLA from the PFC (Fuchs et al. 2007; Mashhoon et al. 2010) suggest that BLA-PFC interactions may be critical for reinstatement of reward seeking. Therefore, BLA may contribute to both extinction and reinstatement via projections to AcbSh and PFC, respectively.

In conclusion, we have shown that AcbSh infusion of the AMPA receptor antagonist, NBQX, attenuates the expression of extinction of alcoholic beer seeking in rats. This effect of NBQX was dose-dependent, behaviorally specific, and dependent on prior extinction training. We also show that pharmacological disconnection of a BLA $\rightarrow$ AcbSh pathway involving AcbSh infusion of NBQX in combination with reversible inactivation of the contralateral BLA attenuates expression of extinction of alcoholic beer seeking in rats. Together, these results support the conclusions that AcbSh AMPA receptors are critical for the expression of extinction of drug and reward seeking behavior and that this role for AcbSh AMPA receptors is dependent on glutamatergic inputs from the BLA.

\section{Materials and Methods}

\section{Subjects}

A total of 68 experimentally naive male Long-Evans rats (Monash Animal Services, Gippsland, Victoria, Australia) weighing 310$330 \mathrm{~g}$ prior to surgery were used in these experiments. Rats were housed in groups of eight and maintained on a 12/12-h light/ dark cycle (lights on at 7:00 a.m.). Food and water were freely available until 1 day before behavioral training, after which rats were allowed 1 -h access to food and water following daily training sessions. All procedures were approved by the Animal Care and Ethics Committee at The University of New South Wales and conducted in accordance with the National Institute of Health (NIH) Guide for the Care and Use of Laboratory Rats (NIH Publications No. $80-23)$, revised in 1996 . The procedures were designed to minimize the number of animals used.

\section{Behavioral apparatus}

All self-administration, extinction training, and tests were conducted in eight standard Med-Associates operant chambers, each enclosed in a sound- and light-attenuating cabinet equipped with a fan that provided constant ventilation and low-level background noise. For all chambers, front (hinged door) and rear walls were constructed of clear Perspex, and end walls were made of stainless steel. The chamber floors comprised stainless steel rods, $4 \mathrm{~mm}$ in diameter, spaced $15 \mathrm{~mm}$ apart (center to center). Inside each chamber, two nosepoke holes containing a white cue-light were symmetrically located on one side wall of the chamber, $3 \mathrm{~cm}$ above the floor. A recessed magazine was located behind a $4 \times 4-\mathrm{cm}$ opening in the center of the same wall between the two nosepokes. The left nosepoke was connected to a syringe pump, whereas responding on the other (inactive) nosepoke did not produce any programmed consequences. There was no illumination in these chambers other than that provided by the white cue-light recessed in the active nosepoke.

For context manipulations used in Experiment 1, there were two sets of chambers. In one set, the chamber floors comprised stainless steel rods, and $\sim 0.1 \mathrm{~mL}$ of dilute rose oil essence was placed in each corner of the bedding beneath the floor. There was no illumination in these chambers other than that provided by the white cue-light recessed in the active nosepoke. In the second set of chambers, the flooring comprised Perspex, and the chambers were illuminated by a $100-\mathrm{mV}$ white house light. Approximately $0.1 \mathrm{~mL}$ of dilute peppermint essence was placed in each corner of the bedding beneath these chambers. These two sets of chambers were counterbalanced to serve as Contexts $\mathrm{A}$ and $\mathrm{B}$.

\section{Surgery}

Rats were injected (i.p.) with the anaesthetic, ketamine $(100 \mathrm{mg} /$ $\mathrm{kg}$ ) and with the muscle relaxant, xylazine $(4 \mathrm{mg} / \mathrm{kg})$. They were shaved and then placed in a stereotaxic frame (Model 900, Kopf) with the incisor bar maintained at $\sim 3.3 \mathrm{~mm}$ below horizontal to achieve a flat skull position. In all experiments, rats were implanted bilaterally with 26-gauge guide cannulae (Plastics One) aimed at ventromedial AcbSh. Flat skull coordinates relative to bregma were $+1.35 \mathrm{~mm}$ anteroposterior $(\mathrm{AP}) ; \pm 0.75 \mathrm{~mm}$ mediolateral (ML); and $-6.5 \mathrm{~mm}$ dorsoventral (DV). In Experiment 4, rats were implanted with bilateral guide cannulae aimed at AcbSh as described above and, additionally, implanted with a unilateral guide cannula targeted at the BLA (flat skull coordinates 
relative to bregma: $-3.0 \mathrm{~mm} \mathrm{AP} ; \pm 5.0 \mathrm{~mm} \mathrm{ML}$; and $-7.65 \mathrm{~mm}$ DV). All guide cannulae were aimed $1 \mathrm{~mm}$ above target site, with coordinates based on the rat brain atlas of Paxinos and Watson (2007). Cannulae were secured to the skull using jeweler's screws and acrylic cement. Obturators with dust caps were fitted to the guide cannulae to prevent occlusion.

Immediately after surgery, rats were injected (s.c.) with the analgesic carprofen $(5 \mathrm{mg} / \mathrm{kg})$ and (i.m.) with antibiotics, procaine penicillin $(75 \mathrm{mg} / \mathrm{kg})$ and cephazolin solution $(50 \mathrm{mg} / \mathrm{kg})$. Rats were given 5-7-d post-operative recovery prior to the start of behavioral procedures, during which time they were monitored and weighed daily.

\section{Intracranial microinfusions}

In all experiments, rats received intracranial microinfusions of saline or the selective and competitive AMPA receptor antagonist, 2,3-Dioxo-6-nitro-1,2,3,4-tetrahydrobenzo[f] quinoxaline-7-sulfonamide disodium salt (NBQX; Tocris Bioscience) directly into the AcbSh. NBQX was dissolved in 0.1 м phosphate-buffered saline. In Experiment 4, rats additionally received unilateral infusions of saline or a solution containing both $\mathrm{GABA}_{\mathrm{B}}$ and $\mathrm{GABA}_{\mathrm{A}}$ agonists, baclofen $(1.0 \mathrm{mM})$ and muscimol hydrobromide $(0.1 \mathrm{mM})$ directly into BLA. All microinfusions were made using 33-gauge cannulae injectors (projecting $1 \mathrm{~mm}$ ventral to the tip of the guide cannula) connected to a $10 \mu \mathrm{L}$ Hamilton syringe via polyethylene-50 tubing, which was mounted onto an infusion pump (KD Scientific). Microinjections were delivered in a volume of $0.5 \mu \mathrm{L}$ per side over $2 \mathrm{~min}$. This volume has been used in previous studies to inactivate the AcbSh separately from adjacent brain regions (Maldonado-Irizarry et al. 1995; Floresco et al. 2008; Fuchs et al. 2008). After allowing an additional $2 \mathrm{~min}$ for diffusion, microinjectors were removed, and rats were returned to their home-cage for $\sim 2 \mathrm{~min}$ before being tested.

\section{Behavioral procedures}

\section{Self-administration and extinction training}

After post-operative recovery, rats were run daily in squads of eight. On the first two days, rats received $2 \times 20$ min magazine training sessions (per day) in the self-administration chamber. During magazine training, rats received 10 noncontingent deliveries of $0.6 \mathrm{~mL}$ decarbonated beer (Coopers Birrell Premium, $<0.5 \% \mathrm{w} / \mathrm{v}$ alcohol content) into the magazine cup at time intervals variable around a mean of $1.2 \mathrm{~min}$. Pure ethanol was added to the beer so that it resembled full strength beer (adjusted to $4 \% \mathrm{v} / \mathrm{v}$ alcohol). Magazine training was identical across all experiments except in Experiment 1, where magazine training took place in both Contexts A and B each day in counterbalanced order. From days $3-9$, rats received daily 1 -h self-administration training sessions. During training, responses on the active nosepoke triggered a syringe pump, delivering $0.6 \mathrm{~mL}$ of $4 \% \mathrm{v} / \mathrm{v}$ alcoholic beer into the magazine cup on an FR-1 schedule of reinforcement and extinguished the white cue-light recessed in the nosepoke during a 24-sec timeout. Responses on the inactive nosepoke did not produce any programmed consequences. Self-administration training was identical across all experiments. However, in Experiment 1 , self-administration training took place in Context A.

Following self-administration, rats underwent daily $1-\mathrm{h}$ extinction sessions for 4 days, except in Experiment 3, where rats received 2 consecutive days of extinction session tests. Procedures for extinction were identical to self-administration, except that syringes were removed from infusion pumps so that responses on the active nosepoke no longer resulted in the delivery of beer. In Experiment 1, extinction training took place in a separate and distinct chamber, Context B. In Experiment 2, rats received one infusion-free extinction session between each of the three microinfusion test sessions.

Prior to each self-administration and extinction session, rats were adapted to the conditions of the intracranial infusion procedure; obturators were removed, and the rats were placed into infusion buckets for $4 \mathrm{~min}$. The obturators were then reinserted, and the rats were returned to their home-cages for $\sim 2$ min before being placed into the chamber for test.

The progressive ratio schedule in Experiment 3 was derived from the function described in Richardson and Roberts (1996) where response ratio equals $\left[5 e^{(\text {reinforcer number } \times 0.2)}\right]-5$, rounded to the nearest integer (i.e., 1, 2, 4, 6, 9, 12, 15, 20, 25, 32, 40, 50 ...). The duration of this test was $90 \mathrm{~min}$.

\section{Histology}

Rats were given an overdose of sodium pentobarbital $(100 \mathrm{mg} / \mathrm{kg}$, i.p.) at the conclusion of the study. Brains were extracted, frozen, and sectioned coronally at $40 \mu \mathrm{m}$ using a cryostat (Microm 560). All sections containing cannula tracts were collected onto glass slides, stained for Nissl substance with cresyl violet, and coverslipped with the mounting agent Entellan. Sections were examined under light microscope to determine cannula tip placements, which were then mapped onto plate sections from the atlas of Paxinos and Watson (2007).

\section{Data analyses}

The mean numbers of active and inactive responses were analyzed using ANOVA with orthogonal contrasts. In Experiment 3, the last completed ratio (i.e., break point) was compared by ANOVA between groups. For all analyses, type I error rate $(\alpha)$ was controlled at 0.05 .

\section{Acknowledgments}

These experiments were supported by an Australian Postgraduate Award to E.Z.M. and by project grants from the National Health and Medical Research Council to G.P.M. (510199, 630406). G.P.M. is an Australian Research Council QEII Fellow (DP0877430).

\section{References}

Crombag HS, Shaham Y. 2002. Renewal of drug seeking by contextual cues after prolonged extinction in rats. Behav Neurosci 116: 169-173.

Crombag HS, Bossert JM, Koya E, Shaham Y. 2008. Context-induced relapse to drug seeking: A review. Phil Trans R Soc B 363: 3233-3243.

de Wit H, Stewart J. 1981. Reinstatement of cocaine-reinforced responding in the rat. Psychopharmacology 75: 134-143.

Engblom D, Bilbao A, Sanchis-Segura C, Dahan L, Perreau-Lenz S, Balland B, Parkitna JR, Luján R, Halbout B, Mameli M, et al. 2008. Glutamate receptors on dopamine neurons control the persistence of cocaine seeking. Neuron 59: 497-508.

Floresco SB, McLaughlin RJ, Haluk DM. 2008. Opposing roles for the nucleus accumbens core and shell in cue-induced reinstatement of food-seeking behavior. Neuroscience 154: 877-884.

Fuchs RA, Weber SM, Rice HJ, Neisewander JL. 2002. Effects of excitotoxic lesions of the basolateral amygdala on cocaine-seeking behavior and cocaine conditioned place preference in rats. Brain Res 929: 15-25.

Fuchs RA, Evans KA, Ledford CC, Parker MP, Case JM, Mehta RH, See RE. 2004. The role of the dorsomedial prefrontal cortex, basolateral amygdala, and dorsal hippocampus in contextual reinstatement of cocaine seeking in rats. Neuropsychopharmacology 30: 296-309.

Fuchs RA, Eaddy JL, Su Z, Bell GH. 2007. Interactions of the basolateral amygdala with the dorsal hippocampus and dorsomedial prefrontal cortex regulate drug context-induced reinstatement of cocaine-seeking in rats. Eur J Neurosci 26: 487-498.

Fuchs RA, Ramirez DR, Bell GH. 2008. Nucleus accumbens shell and core involvement in drug context-induced reinstatement of cocaine seeking in rats. Psychopharmacology (Berl) 200: 545-556.

Ghasemzadeh MB, Vasudevan P, Mueller C, Seubert C, Mantsch JR. 2009. Neuroadaptations in the cellular and postsynaptic group 1 metabotropic glutamate receptor mGluR5 and Homer proteins following extinction of cocaine self-administration. Neurosci Lett 452: $167-171$.

Groenewegen HJ, Wright CI, Beijer AVJ, Voorn P. 1999. Convergence and segregation of ventral striatal inputs and outputs. Ann NY Acad Sci 877: $49-63$.

Hamlin AS, Clemens KJ, Choi EA, McNally GP. 2009. Paraventricular thalamus mediates context-induced reinstatement (renewal) of extinguished reward seeking. Eur J Neurosci 29: 802-812. 
Heimer L, Alheid GF, de Olmos JS, Groenewegen HJ, Haber SN, Harlan RE, Zahm DS. 1997. The accumbens: Beyond the core-shell dichotomy. J Neuropsychiatry Clin Neurosci 9: 354-381.

Hoover WB, Vertes RP. 2007. Anatomical analysis of afferent projections to the medial prefrontal cortex in the rat. Brain Struct Funct 212: 149-179.

Hu X-T, White FJ. 1996. Glutamate receptor regulation of rat nucleus accumbens neurons in vivo. Synapse 23: 208-218.

Jewett DC, Cleary J, Levine AS, Schaal DW, Thompson T. 1995. Effects of neuropeptide Y, insulin, 2-deoxyglucose, and food deprivation on food-motivated behavior. Psychopharmacology 120: 267-271.

Kalivas PW, Volkow ND. 2005. The neural basis of addiction: A pathology of motivation and choice. Am J Psychiatry 162: 1403-1413.

Kirouac GJ, Ganguly PK. 1995. Topographical organization in the nucleus accumbens of afferents from the basolateral amygdala and efferents to the lateral hypothalamus. Neuroscience 67: 625-630.

Kita H, Kitai ST. 1990. Amygdaloid projections to the frontal cortex and the striatum in the rat. J Comp Neurol 298: 40-49.

Krause M, German PW, Taha SA, Fields HL. 2010. A pause in nucleus accumbens neuron firing Is required to initiate and maintain feeding. J Neurosci 30: 4746-4756.

Maldonado-Irizarry CS, Swanson CJ, Kelley AE. 1995. Glutamate receptors in the nucleus accumbens shell control feeding behavior via the lateral hypothalamus. J Neurosci 15: 6779-6788.

Marchant NJ, Hamlin AS, McNally GP. 2009. Lateral hypothalamus is required for context-induced reinstatement of extinguished reward seeking. J Neurosci 29: 1331-1342.

Mashhoon Y, Wells AM, Kantak KM. 2010. Interaction of the rostral basolateral amygdala and prelimbic prefrontal cortex in regulating reinstatement of cocaine-seeking behavior. Pharmacol Biochem Behav 96: $347-353$.

McLaughlin RJ, Floresco SB. 2007. The role of different subregions of the basolateral amygdala in cue-induced reinstatement and extinction of food-seeking behavior. Neuroscience 146: 1484-1494.

McLaughlin J, See RE. 2003. Selective inactivation of the dorsomedial prefrontal cortex and the basolateral amygdala attenuates conditioned-cued reinstatement of extinguished cocaine-seeking behavior in rats. Psychopharmacology 168: 57-65.

Millan EZ, Furlong TM, McNally GP. 2010. Accumbens shell-hypothalamus interactions mediate extinction of alcohol seeking. J Neurosci 30: $4626-4635$

O'Donnell P, Grace AA. 1995. Synaptic interactions among excitatory afferents to nucleus accumbens neurons: Hippocampal gating of prefrontal cortical input. J Neurosci 15: 3622-3639.

O'Donnell P, Greene J, Pabello N, Lewis BL, Grace AA. 1999. Modulation of cell firing in the nucleus accumbens. Ann NY Acad Sci 877: 157-175.

Paxinos G, Watson C. 2007. The rat brain in stereotaxic coordinates. Elsevier, New York, NY.

Peters J, LaLumiere RT, Kalivas PW. 2008. Infralimbic prefrontal cortex is responsible for inhibiting cocaine seeking in extinguished rats. J Neurosci 28: 6046-6053.
Richardson NR, Roberts DCS. 1996. Progressive ratio schedules in drug self-administration studies in rats: A method to evaluate reinforcing efficacy. J Neurosci Methods 66: 1-11.

Robinson TG, Beart PM. 1988. Excitant amino acid projections from rat amygdala and thalamus to nucleus accumbens. Brain Res Bull 20: 467-471.

Sandstrom MI, Rebec GV. 2003. Characterization of striatal activity in conscious rats: Contribution of NMDA and AMPA/kainate receptors to both spontaneous and glutamate-driven firing. Synapse 47: 91-100.

Sano H, Yokoi M. 2007. Striatal medium spiny neurons terminate in a distinct region in the lateral hypothalamic area and do not directly innervate orexin/hypocretin- or melanin-concentrating hormone-containing neurons. J Neurosci 27: 6948-6955.

Self DW, Choi K, Simmons D, Walker JR, Smagula CS. 2004. Extinction training regulates neuroadaptive responses to withdrawal from chronic cocaine self-administration. Learn Mem 11: 648-657.

Stratford TR, Kelley AE. 1999. Evidence of a functional relationship between the nucleus accumbens shell and lateral hypothalamus subserving the control of feeding behavior. J Neurosci 19: 11040-11048.

Sutton MA, Schmidt EF, Choi K-H, Schad CA, Whisler K, Simmons D, Karanian DA, Monteggia LM, Neve RL, Self DW. 2003. Extinction-induced upregulation in AMPA receptors reduces cocaine-seeking behavior. Nature 421: 70-75.

Taha SA, Fields HL. 2005. Encoding of palatability and appetitive behaviors by distinct neuronal populations in the nucleus accumbens. J Neurosci 25: $1193-1202$.

Taha SA, Fields HL. 2006. Inhibitions of nucleus accumbens neurons encode a gating signal for reward-directed behavior. J Neurosci 26: 217-222.

Tye KM, Cone JJ, Schairer WW, Janak PH. 2010. Amygdala neural encoding of the absence of reward during extinction. J Neurosci 30: $116-125$.

Tzschentke TM, Schmidt WJ. 2003. Glutamatergic mechanisms in addiction. Mol Psychiatry 8: 373-382.

Wright CI, Beijer AV, Groenewegen HJ. 1996. Basal amygdaloid complex afferents to the rat nucleus accumbens are compartmentally organized. J Neurosci 16: 1877-1893.

Yun IA, Nicola SM, Fields HL. 2004. Contrasting effects of dopamine and glutamate receptor antagonist injection in the nucleus accumbens suggest a neural mechanism underlying cue-evoked goal-directed behavior. Eur J Neurosci 20: 249-263.

Zhang M, Balmadrid C, Kelley A. 2003. Nucleus accumbens opioid, GABaergic, and dopaminergic modulation of palatable food motivation: Contrasting effects revealed by a progressive ratio study in the rat. Behav Neurosci 117: 202-211.

Received January 13, 2011; accepted in revised form March 31, 2011. 


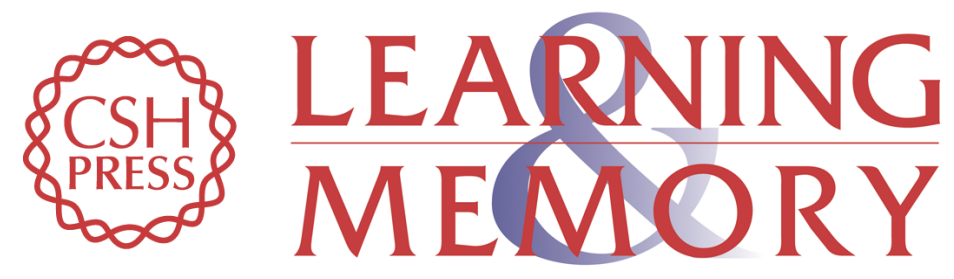

\section{Accumbens shell AMPA receptors mediate expression of extinguished reward seeking through interactions with basolateral amygdala}

E. Zayra Millan and Gavan P. McNally

Learn. Mem. 2011, 18:

Access the most recent version at doi:10.1101//m.2144411

References This article cites 43 articles, 13 of which can be accessed free at: http://learnmem.cshlp.org/content/18/7/414.full.html\#ref-list-1

License

Email Alerting

Service

Receive free email alerts when new articles cite this article - sign up in the box at the top right corner of the article or click here. 